\title{
Effects of live-shearing on population parameters and movement in sedentary and migratory populations of guanacos Lama guanicoe
}

\author{
Pablo D. Carmanchahi, Natalia M. Schroeder, María José Bolgeri \\ R. Susan Walker, Martín Funes, Jodi Berg, Paula Taraborelli \\ Ramiro Ovejero, Pablo Gregorio, Pablo Moreno and Andrés J. Novaro
}

\begin{abstract}
Live-shearing of wild guanacos Lama guanicoe may affect their reproductive success and population resilience, and therefore it is important to assess the biological sustainability of obtaining their wool. We evaluated effects of capture and shearing on survival and reproduction, population parameters, daily movements, ranging behaviour and spatial distribution in sedentary and migratory populations. We assessed population variables by radio-telemetry and line-transect surveys before and after capture. We estimated high post-shearing survival rates in both populations and similar yearling production in shorn and non-shorn females in the migratory population. We did not find significant variations in density and population structure before and after shearing in the sedentary population, whereas in the migratory population density decreased and the population structure changed significantly after assembly of the capture structure, returning to pre-assembly levels 1 month later. The mean daily distance moved by radio-collared guanacos during the first 2 days after shearing was three times longer than during the following 30 days. There was a $25 \%$ decrease in the mean home-range size of shorn guanacos between the first and second month after shearing but this decline appeared to be associated with a seasonal change in movement, because a similar reduction occurred during the same period
\end{abstract}

Pablo D. Carmanchahi (Corresponding author) and Pablo Gregorio Grupo de Investigaciones en Ecofisiología de Fauna Silvestre, INIBIOMA-CONICET, UNCo-AUSMA, Pasaje de la Paz 235, San Martín de los Andes (8370), Neuquén, Argentina. E-mail pablocarman@gmail.com

Natalia M. Schroeder and Paula Taraborelli Grupo de Investigaciones en Ecofisiología de Fauna Silvestre and Laboratorio de Desertificación y Ordenamiento Territorial, IADIZA, CCT-Mendoza, CONICET, Argentina

María José Bolgeri and Andrés J. Novaro Programa Estepa Patagónica y Andina, INIBIOMA-CONICET-UNComa and Wildlife Conservation Society, Junín de los Andes, Neuquén, Argentina

R. Susan Walker, Martín Funes and Jodi Berg Programa Estepa Patagónica y Andina, Wildlife Conservation Society, Junín de los Andes, Neuquén, Argentina

RAMIRo Ovejero Grupo de Investigaciones en Ecofisiología de Fauna Silvestre and GIB, IADIZA, CCT-Mendoza, CONICET, Argentina

Pablo Moreno Grupo de Investigaciones en Ecofisiología de Fauna Silvestre and Laboratorio de Ecología de Enfermedades, Fac.Cs.Veterinarias, UNL, Santa Fe, Argentina

Received 13 December 2012. Revision requested 22 May 2013.

Accepted 13 January 2014. First published online 22 July 2014. the following year, when the guanacos were not shorn. Live-shearing modified the spatial distribution pattern in the sedentary population but did not have a significant effect on the migratory population. Management of guanacos may contribute towards developing a biologically sustainable economic activity that promotes conservation of wildlife and habitats.

Keywords Arid ecosystem, biodiversity conservation, Lama guanicoe, population parameters, sustainable use, wild guanacos, wildlife management

\section{Introduction}

The guanaco Lama guanicoe is the dominant wild 1 herbivore in the Andean steppe and plays a central role in South American arid ecosystems. It is a social species, with a social structure that includes family groups, bachelor groups and single males. Franklin \& Fritz (1991) described sedentary and migratory guanaco populations, indicating that populations tend to be sedentary where forage resources are easily defensible, allowing territorial males to maintain their territories throughout the year. In contrast, where forage and water are limited and weather conditions are adverse in some seasons, groups or individuals do not have permanent territories but migrate between seasonal ranges.

Guanaco populations have declined by $>90 \%$ throughout most of their range during the last 100 years (Baldi et al., 2010). Habitat desertification as a result of overgrazing by domestic livestock has occurred in the arid Patagonia region of Argentina, which holds the greatest abundance of guanacos. Other factors in the species' decline include forage competition with sheep, indiscriminate legal and illegal hunting, and the negative perception of the guanaco among local people (Raedeke, 1979; Baldi et al., 2001, 2010). With the inclusion of the guanaco in Appendix II of CITES in 1993 (CITES, 2013) it was recommended that countries did not import guanaco products from Argentina, which resulted in a decline in commercial hunting of guanacos. Argentinian legislation only allows the export of guanaco fibre obtained from live individuals, which can be achieved by breeding animals in captivity or by management of wild 
guanacos. Private and government initiatives have been developed to obtain fibre through capture, shearing and subsequent release of wild guanacos (Montes et al., 2006; Carmanchahi et al., 2011). However, stress associated with these activities in such a social species may reduce its reproductive success and resilience, and therefore knowledge of the biological effects of live-shearing, both on migratory and sedentary populations, is required.

Studies of the physiological effects of shearing have shown that stress levels, measured through cortisol levels, increase significantly with handling time during capture and shearing of wild guanacos (Carmanchahi et al., 2011). In addition, behavioural indicators show an increase in stress levels among larger groups of guanacos in round-up corrals (Taraborelli et al., 2011). However, mortality during shearing is generally low (Baldi et al., 2010; Rey et al., 2012b). There is limited information available about the effects of management on population parameters and behavioural responses after guanacos are released, and no data on effects on migratory populations.

Our objective is to evaluate the effects of round-up and shearing on density, group size, spatial distribution, survival, reproduction and movement in sedentary and migratory populations of wild guanacos in northern Patagonia, Argentina. We hypothesize that shearing of wild guanacos affects these parameters less in populations living in open areas with few barriers than in sedentary populations in areas with fences for livestock, which impose restrictions on daily and seasonal movements in search of forage.

\section{Study area}

We conducted our study at two sites where capture and handling of wild guanacos have occurred since 2005, following the methodology described in Carmanchahi et al. (2011) and Taraborelli et al. (2011). Management conditions at the sites differ in terms of the number of guanacos shorn per year, livestock densities, presence of wire fences, and land ownership.

The first site is a sheep ranch in Río Negro province (Fig. 1), which harbours a sedentary population of wild guanacos (20.4 $\pm \mathrm{SE} 2.7$ guanacos per $\mathrm{km}^{2}$; P.D. Carmanchahi \& M. Funes, unpubl. data). The ranch covers $400 \mathrm{~km}^{2}$ (divided by a $1.3 \mathrm{~m}$ high fence into seven paddocks of $50 \mathrm{~km}^{2}$ and two of $25 \mathrm{~km}^{2}$ ), with c. 25 sheep per $\mathrm{km}^{2}$ (P.D. Carmanchahi \& M. Funes, unpubl. data). Guanacos are captured and shorn in four of the paddocks, where capture and shearing structures are in place year-round. Vegetation is characterized by low shrubby steppe, with a transition between Patagonian Steppe and Monte Desert phytogeographical provinces (León et al., 1998). Small canyons, tablelands and valleys dominate the physiography. This

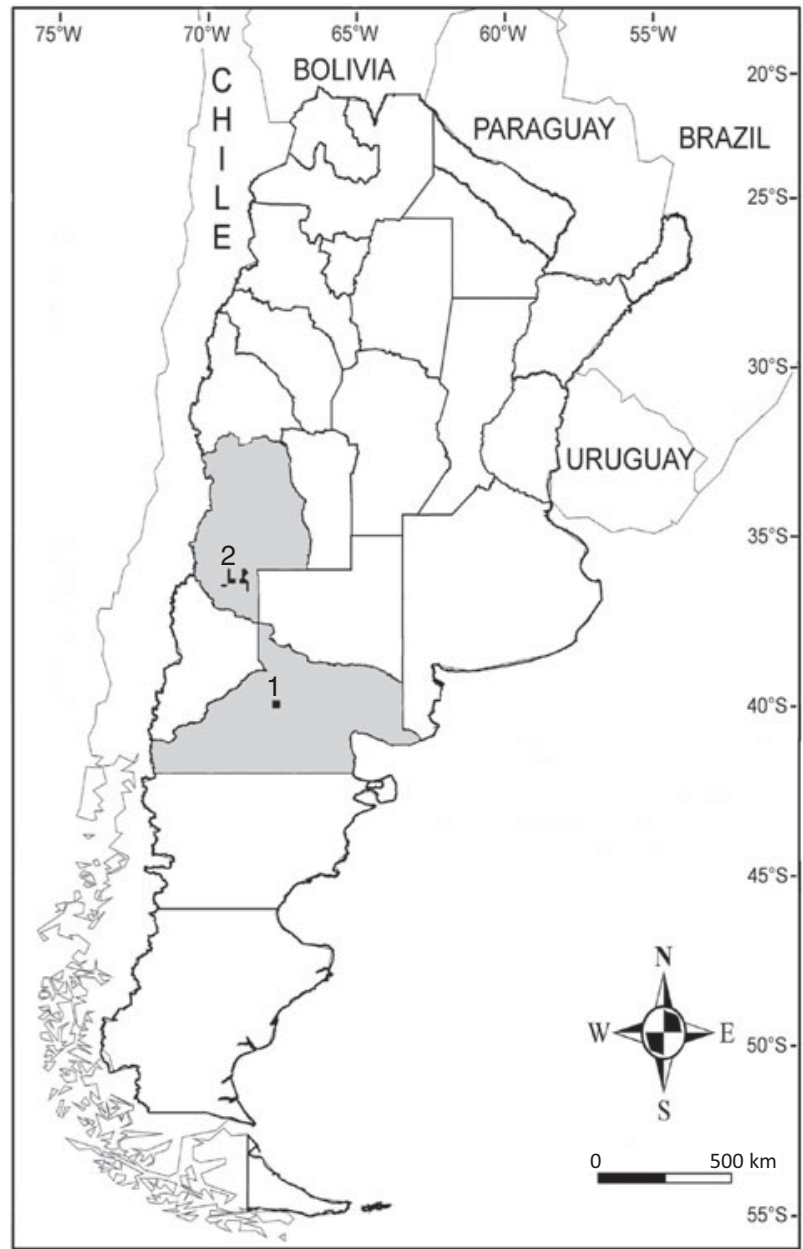

FIG. 1 The study sites in Argentina where we investigated the effects of capture and shearing on populations of guanacos Lama guanicoe: a sheep ranch in Río Negro province (1), and La Payunia Provincial Reserve, in Mendoza province (2).

region has a desert climate, with mean annual precipitation of $<200 \mathrm{~mm}$, concentrated in autumn and winter. Mean annual temperature is $10-12{ }^{\circ} \mathrm{C}$.

The second site is La Payunia Provincial Reserve, in southern Mendoza province (Fig. 1). This region is a semiarid biome of the La Payunia phytogeographical province within the Andean-Patagonian domain (Martínez Carretero, 2004) and has a desert climate, with mean annual precipitation of $255 \mathrm{~mm}$ and a mean temperature of $6{ }^{\circ} \mathrm{C}$ in winter and $20{ }^{\circ} \mathrm{C}$ in summer. The Reserve covers $6,400 \mathrm{~km}^{2}$, of which 2,000 are state-owned lands, and supports the largest known migratory population of guanacos in central Argentina, with up to 26,000 individuals in spring (Schroeder, 2013). Mean annual livestock densities for the northern part of the Reserve (c. 1,200 $\mathrm{km}^{2}$ ) were estimated at $7.89 \mathrm{~km}^{-2}$ for small livestock (goats and sheep) and $3.55 \mathrm{~km}^{-2}$ for large livestock (cattle and horses; Schroeder, 2013).

Every year, the provincial wildlife agency authorizes a cooperative of small-scale herders who inhabit the 
periphery of the Reserve to capture and shear guanacos. As this occurs inside a protected area a mobile structure for capture and handling of guanacos and a temporary camp must be set up by the herders and dismantled completely afterwards. The camp houses c. 40 herders for 25-30 days.

\section{Methods}

Wild guanacos were rounded up and driven into a corral trap (described in Carmanchahi et al., 2011) by horse riders, and handled according to a welfare protocol (Carmanchahi \& Marull, 2012) approved by the Wildlife Departments of Mendoza and Río Negro provinces and the National Wildlife Department. Shorn individuals were fitted with coloured, numbered collars and then released.

We conducted ground surveys of guanacos at both study sites, using the line-transect method (Buckland et al., 2001), making observations from the back of an open truck while driving along secondary roads and trails at $10-30 \mathrm{~km}$ per hour. We recorded the number of guanacos in each group, the radial distance to the animal or to the centre of the group (measured with a laser range-finder with accuracy $\pm 1 \mathrm{~m}$ ), and the angle between the transect and the centre of the group (measured with a compass). We recorded the geographical coordinates of each sighting, using a global positioning system (GPS). At the sheep ranch the surveyed area was $250 \mathrm{~km}^{2}$, with a sampling effort of $81.7 \mathrm{~km}$, and at the Reserve the surveyed area was $200 \mathrm{~km}^{2}$, with a sampling effort of $75 \mathrm{~km}$.

At the sheep ranch capture and shearing were carried out at the post-partum stage (January) in 2005 and 2007. At the Reserve capture and shearing were carried out during the pre-partum stage (September-October) during 2005-2010 (except 2008). As guanaco offspring are already mobile and able to follow their mother in January we consider it valid to compare movement parameters and social organization of guanacos among populations shorn before and after the birthing period.

At the sheep ranch a search for dead guanacos was conducted on horseback 10 days after capture and shearing, and additional surveys were conducted by vehicle 15-30 days thereafter on all the trails within each paddock. Ground surveys and radio-collars were used to assess the survival of shorn guanacos at the Reserve. Ten adult males and 22 adult females were fitted with radio-collars (six GPS and 26 VHF) during 4 years (2005, 2006, 2007 and 2009). Guanacos were tracked on the ground by MJB and JB, daily during the first 2 weeks after capture and 2-3 times per week afterwards, and occasionally from a fixed-wing aircraft. We estimated the date of death and cause of mortality of radiocollared guanacos through visual inspection of carcasses, and assessed nutritional condition by examining the colour and consistency of femoral marrow fat (Harder \&
Kirkpatrick, 1994). We estimated the survival rate of radiocollared guanacos during the first year after round-up, using the Kaplan-Meier method (Pollock et al., 1989), combining data from round-up events during 2005-2009 to increase sample sizes.

We attempted to observe radio-collared guanacos during the breeding season, during 2005-2009, to determine the proportion of females with young after the animals were rounded up and shorn. However, it was difficult to approach radio-collared guanacos because of the paucity of trails in the Reserve. Less than $1 \%$ of triangulations led to sightings and we were able to assess the proportion of females with young for a sample of only 14 radio-collared females.

We assessed changes in activity by measuring daily distances moved and home range sizes of guanacos that were shorn and released in the Reserve. Given the low precision of VHF collars, daily distances moved are reported only for guanacos with GPS collars and home range sizes are estimated separately for guanacos with GPS and VHF collars. As we did not have movement data prior to capture and shearing or for non-shorn guanacos, we compared daily distances moved during the first 2 days after shearing and release to distances moved in the following 30 days, and compared home range sizes during the first 30 days after shearing with sizes 30-60 days after shearing. To assess whether changes in movement were associated with seasonal variation we also reported daily movements and home range sizes during the same periods the following year. We could not estimate monthly home ranges based on VHF data, as we did for GPS data, and therefore we grouped VHF data for the 2 months after shearing and compared this home range estimate with that for the same period the following year. Distances moved and home range sizes were compared using generalized linear models, considering guanacos as a random effect because of the high variability among individuals (Hoffmann, 2004).

To evaluate changes in the parameters of the migratory population we conducted surveys at the Reserve, considering the camp installation and setting up of the capture structure as disturbance factors. We carried out pre-camp surveys 3 days before starting to build the capture structure and the camp, and pre-capture surveys 2 days before the round-up and capture events. We performed surveys 1-2 days after capture, shearing and release, to detect immediate effects, and c. 1 month later to detect long-term effects. At the sheep ranch we only tested long-term effects, conducting post-shearing surveys 15-30 days after shearing.

We used Distance v. 5.o (Buckland et al., 2001) to calculate individual and group density (guanacos per $\mathrm{km}^{2}$ and groups per $\mathrm{km}^{2}$, respectively) and group size (guanacos per group). We chose the best model based on the Akaike information criterion, goodness-of-fit tests and visual assessment of data in histograms (Buckland et al., 2001). We investigated whether detection probability was related 
to group size, as this can result in overestimation of density. We carried out a regression among the natural logarithms of group size and the detection probability of each group, with a significance level of $\mathrm{P}<0.15$ (Buckland et al., 2001). We used ANOVA to compare group and guanaco densities and mean group size pre- and post-shearing at the sheep ranch, and pre-camp, pre-capture, and immediate and late postshearing at the Reserve. Post-hoc testing (Tukey test, $\mathrm{P}<0.05$ ) was used to test for differences among variables.

To assess whether the installation of the camp and capture events influenced the spatial distribution of guanacos we divided the study area into regular intervals of $1 \mathrm{~km}$ (sheep ranch) and $2 \mathrm{~km}$ (Reserve) from the shearing corral. Different spatial resolution was used at the two sites because of differences in the number of individuals observed and their natural dispersion. We recorded the number of individuals and the mean group size along transects within each distance interval. We standardized the observations according to the number of kilometres surveyed per distance interval. For the sheep ranch we evaluated the effect of three independent capture events in three paddocks during 2005. As wire fences are semi-permeable barriers that cause direct mortality and are rarely crossed by wild guanacos (Rey et al., 2012a), we considered the guanaco subpopulations of each paddock to be independent and analysed each as a replicate. For the Reserve we evaluated the effect of camp installation during 2009 and 2010. For each year we used portions of ground surveys of $0.7-7.4 \mathrm{~km}$ (2009) and 1.3-10 km (2010) as sampling units. To ensure independence, fragments were separated by at least $1 \mathrm{~km}$. We used a Friedman nonparametric block ANOVA to compare the number of individuals and group size per $\mathrm{km}$ pre- and post-shearing at both sites. IDRISI Taiga v. 16.05 was used for spatial analyses and InfoStat (Di Rienzo et al., 2011) and R (R Development Core Team, 2012) for statistical analyses.

\section{Results}

\section{Survival and reproduction}

Of the 32 radio-collared guanacos in La Payunia Provincial Reserve, one female died 10 days after shearing in 2007, within the period of high risk of capture myopathy. The results of a necropsy indicated that the guanaco was in good physical condition, with no signs of disease or predation, but no signs of capture myopathy were detected in an analysis of tissue samples (V. Rago, pers. comm.). The remaining 31 guanacos survived during the year after capture. We therefore estimate an annual post-shearing survival rate of $0.98 \pm$ SE 0.02

At the end of the reproductive season (March-April) in the Reserve we were able to observe 9 out of 12 and 5 out of 6 adult females shorn and radio-collared in 2006 and 2007, respectively. Of these, two females radio-collared in 2006 and four radio-collared in 2007 had young, indicating an overall mean proportion of 0.43 during the study period.

Of the 658 guanacos captured in the Reserve during 2006, 2007, 2009 and 2010 only two shorn individuals were found dead during post-shearing surveys, and therefore we estimate a maximum post-shearing survival rate of $0.997 \pm$ SE 0.001 .

At the sheep ranch 2,934 guanacos were captured during five capture and shearing events, and five were subsequently found dead, yielding an estimated maximum post-shearing survival rate of $0.99 \pm$ SE 0.01 .

\section{Movement}

At the Reserve the mean daily distance moved by the six guanacos with GPS collars was $9.1 \pm$ SE $1.94 \mathrm{~km}$ during the first 2 days after release and $3.6 \pm \mathrm{SE} 0.54 \mathrm{~km}$ during the following 30 days $(F=6.31, \mathrm{P}=0.05$; random effect not significant: $F=0.848, \mathrm{P}=0.57)$. Four guanacos moved $>10 \mathrm{~km}$ (up to $17 \mathrm{~km}$ ) during the first 2 days after capture. The mean daily distance moved by the six guanacos with GPS collars during the same month the following year was $2.9 \pm \mathrm{SE} 0.42 \mathrm{~km}$.

The mean home range of the six guanacos with GPS collars was $220 \pm \mathrm{SE} 51 \mathrm{~km}^{2}$ during the month immediately after shearing and declined by $25 \%$, to $166 \pm$ SE $26 \mathrm{~km}^{2}$, during the following month, although this decline was not significant $(F=0.67, \mathrm{P}=0.45$; random effect: $F=0.48$, $\mathrm{P}=0.78)$. The mean home range of the same guanacos during the month beginning 1 year after the shearing date was $187 \pm$ SE $63 \mathrm{~km}^{2}$ (15\% smaller than the previous year) and had declined by $31 \%$ a month later, to $129 \pm$ SE $59 \mathrm{~km}^{2}$. Similarly, the mean home range of 25 guanacos with VHF collars declined by $23 \%$ between the 2 months immediately after shearing $\left(169 \pm \mathrm{SE} 136 \mathrm{~km}^{2}\right)$ and the same 2 months 1 year later $\left(130 \pm \mathrm{SE} 132 \mathrm{~km}^{2} ; F=2.178, \mathrm{P}=0.154\right)$, with significant differences among individuals (random effect: $F=3.728, \mathrm{P}=0.002$; ranges were $33-596 \mathrm{~km}^{2}$ during the year of capture and $40-425 \mathrm{~km}^{2}$ during the following year). Females contributed more than males to this overall decline: $75 \%$ of females had second-year home ranges that were $35-74 \%$ smaller than in the first year, whereas only $30 \%$ of males had home ranges that were $>20 \%$ smaller than in the first year. For all other guanacos of both sexes home ranges during the second year were larger or $<20 \%$ smaller than in the first year.

\section{Density and population structure}

In the sedentary population at the sheep ranch there were no significant differences in group density $(F=0.14, \mathrm{P}=0.72$, $\mathrm{df}=1, \mathrm{n}=12$; Fig. 2a), guanaco density $(F=1.79, \mathrm{P}=0.21$, 

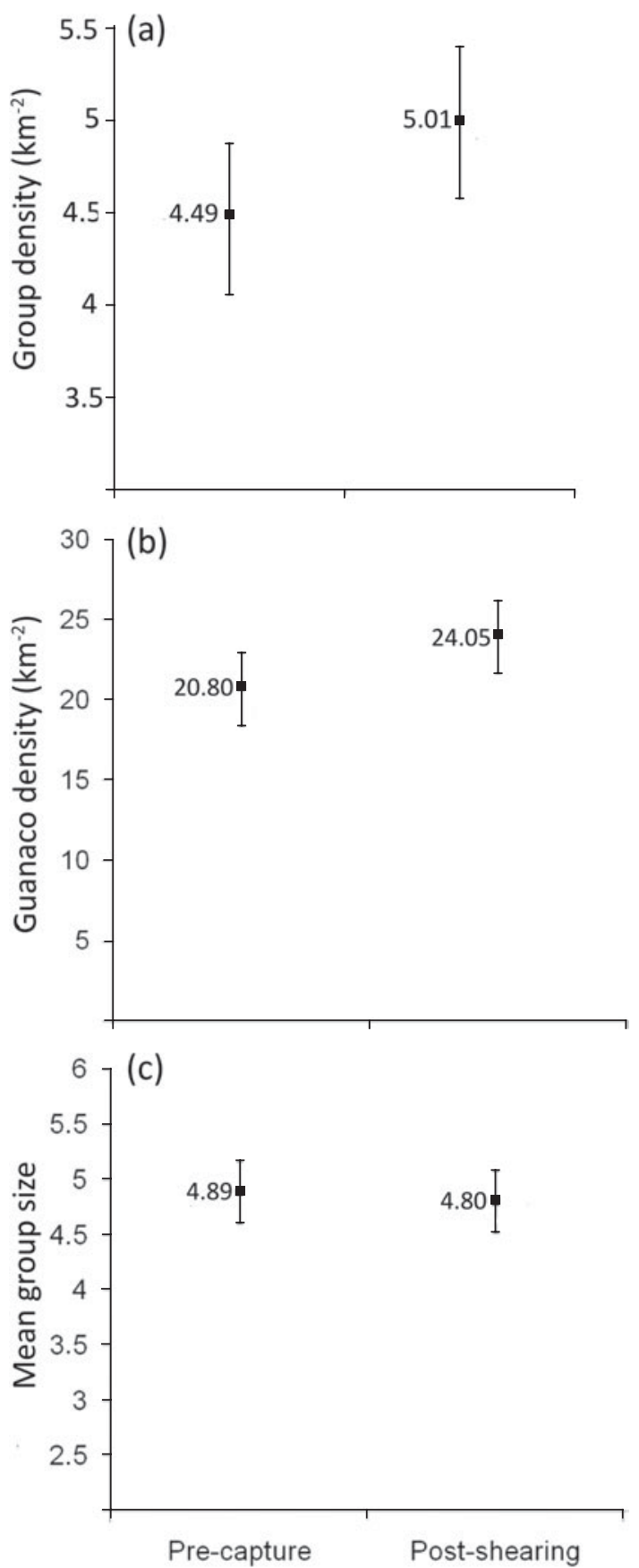

FIG. 2 Population parameters pre-capture and post-shearing for guanacos on the sheep ranch in Rio Negro province (Fig. 1): (a) group density, (b) population density, and (c) mean group size. None of the values are significantly different (post-hoc Tukey test, $\mathrm{P}<0.05)$.

$\mathrm{df}=1, \mathrm{n}=12 ;$ Fig. $2 \mathrm{~b})$ or mean group size $(F=1.75$, $\mathrm{P}=0.22, \mathrm{df}=1, \mathrm{n}=12$; Fig. $2 \mathrm{c}$ ) before and after round-up and shearing.

At the Reserve there was a significant decline in guanaco density $(F=19.46, \mathrm{P}=0.0001, \mathrm{df}=11, \mathrm{n}=4$; Fig. $3 \mathrm{~b})$ and mean group size $(F=15.5, \mathrm{P}=0.0007, \mathrm{df}=9, \mathrm{n}=4$; Fig. 3c) after installation of the camp and the capture
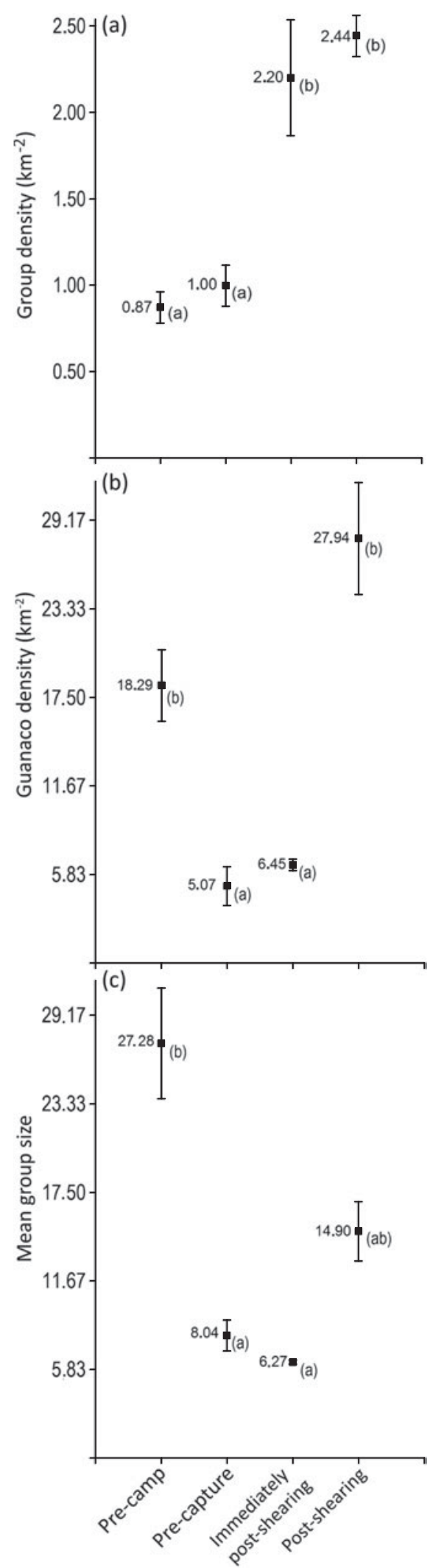

FIG. 3 Population parameters pre-capture and post-shearing for guanacos in La Payunia Provincial Reserve, Mendoza province (Fig. 1): (a) group density, (b) population density, and (c) mean group size. Different letters indicate $\mathrm{P}<0.05$ by post-hoc Tukey test. 

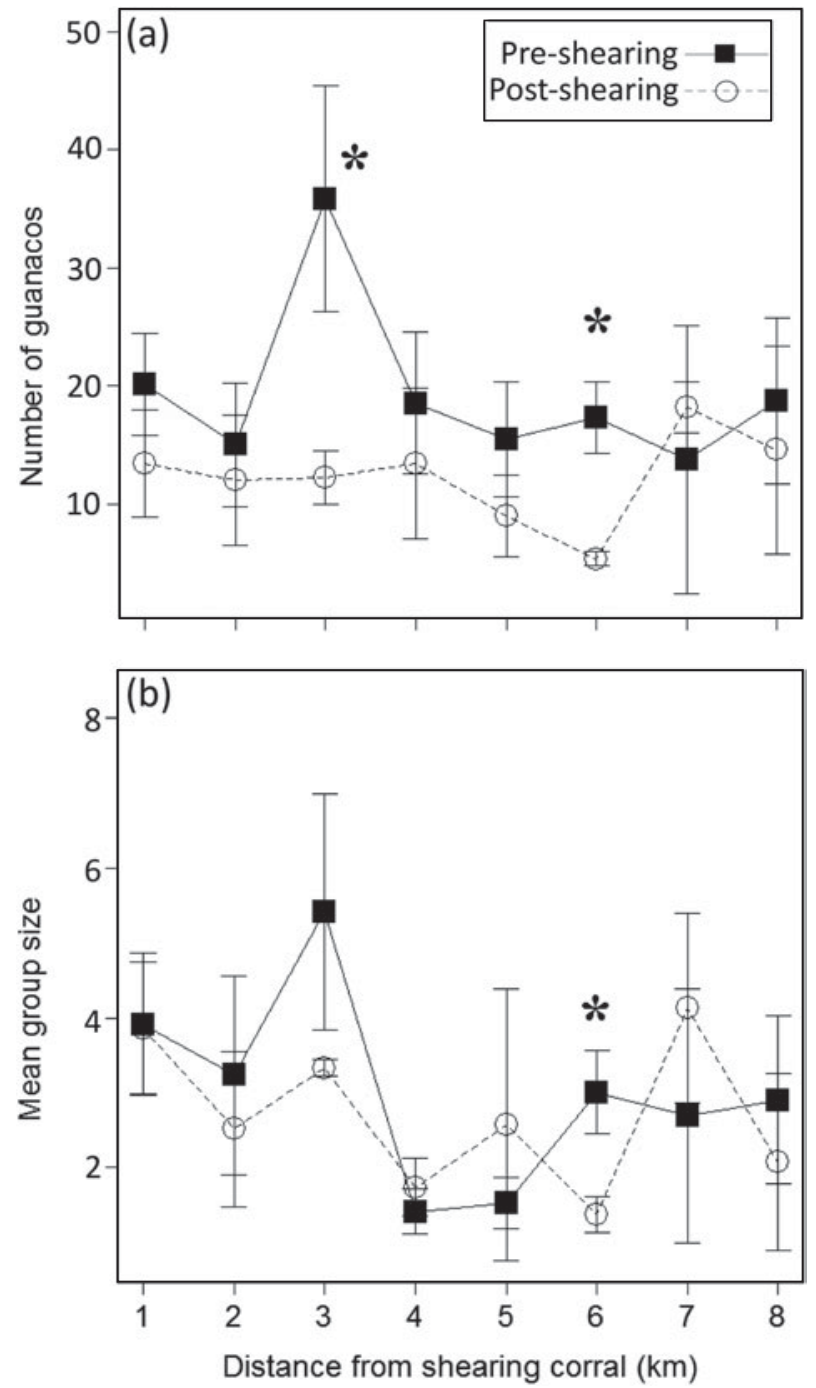

FIG. 4 Mean number of guanacos \pm SE (a) and mean group size $\pm S E$ (b) with distance from the shearing corral before and after the shearing events on the sheep ranch during 2005.

structure, whereas a similar group density was maintained. Group density (but not guanaco density or group size) was significantly greater in surveys immediately post shearing $(F=19.95, \mathrm{P}=0.0003, \mathrm{df}=9, \mathrm{n}=4$; Fig. $3 \mathrm{a})$ compared to levels after installation of the camp and capture structure. One month after shearing, guanaco density was similar to that estimated prior to management activities $(F=19.5$, $P=0.0001, d f=11, n=4$, Fig. 3b).

\section{Spatial distribution}

At the sheep ranch pre-capture densities were greater than post-shearing densities up to $6 \mathrm{~km}$ from the shearing corral but these differences were significant only at $3 \mathrm{~km}$ (precapture: $35.86 \pm$ SE 9.6 individuals per km; post-shearing: $12.24 \pm \mathrm{SE} 2.29$ individuals per $\mathrm{km} ; T^{2}={ }_{1} \mathrm{E}_{3} \mathrm{O}, \mathrm{P}<0.0001$;
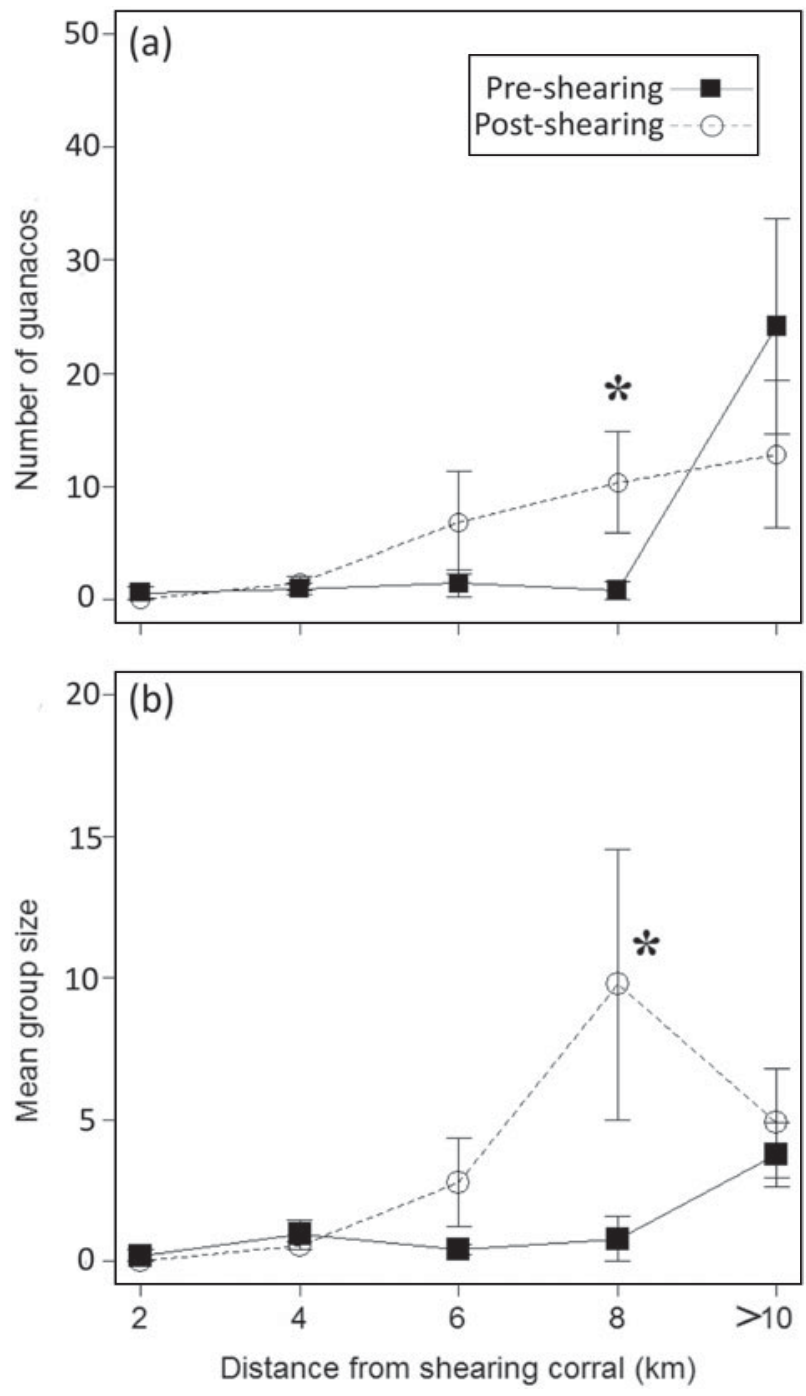

FIG. 5 Mean number of guanacos \pm SE (a) and mean group size \pm SE (b) with distance from the shearing corral before and after installation of the camp in La Payunia Provincial Reserve in 2009 and 2010.

Fig. 4 a) and at $6 \mathrm{~km}$ (pre-capture: $17.32 \pm \mathrm{SE} 3.05$ individuals per $\mathrm{km}$; post-shearing: $5.37 \pm \mathrm{SE} 0.61$ individuals per $\mathrm{km}$; $T^{2}={ }_{1} E_{30}$, $\mathrm{P}<0.0001$; Fig. 4a). The mean group size was significantly higher pre-capture (3.01 \pm SE 0.56 individuals per group) than post-shearing (1.38 $\pm \mathrm{SE} 0.24$ individuals per group; $T^{2}={ }_{1} \mathrm{E}_{3} \mathrm{O}, \mathrm{P}<0.0001$; Fig. $4 \mathrm{~b}$ ) only at $6 \mathrm{~km}$ from the shearing corral.

At the Reserve pre-capture density was significantly lower before than after installation of the camp $(0.78 \pm$ SE 0.8 individuals per $\mathrm{km}$ and $10.36 \pm$ SE 4.46 individuals per $\mathrm{km}$, respectively; $T^{2}={ }_{1} \mathrm{E}_{3} \mathrm{O}, \mathrm{P}<0.0001$; Fig. 5a) at $8 \mathrm{~km}$ from the shearing corral. Mean group size was also smaller before than after installation of the camp $(0.79 \pm \mathrm{SE} \pm 0.8$ individuals per group and $9.79 \pm \mathrm{SE} 4.8$ individuals per group, respectively; $T^{2}={ }_{1} \mathrm{E}_{3} \mathrm{O}, \mathrm{P}<0.0001$; Fig. 5b), only at $8 \mathrm{~km}$ from the shearing corral. 


\section{Discussion}

\section{Effects on survival and reproduction}

The survival rate of shorn guanacos in the Reserve was higher than the rates estimated in the only other reported study on shorn guanacos, at Cabeza de Vaca ranch (Rey et al., 2012b). At Cabeza de Vaca the annual survival rate estimated from telemetry of 17 shorn adult guanacos was $0.70 \pm$ SE 0.11, whereas survival estimated from 1,334 capture-recapture histories was $0.82 \pm \mathrm{SE} 0.01$. Lower survival at Cabeza de Vaca ranch than in La Payunia Reserve may be attributable to various factors, including restriction of guanaco movements by fences, competition with sheep (Rey et al., 2012a) and differences in handling protocols.

Capture and shearing do not appear to have affected reproduction of guanacos in La Payunia, based on our results for radio-collared individuals. The mean proportion of yearlings associated with shorn radio-collared females at the end of the breeding season (0.43) was similar to the proportion of yearlings in the population, estimated from transect surveys during the same period ( $0.43 \pm$ SE 0.21 ; M. Bolgeri \& A. Novaro, unpubl. data). This similarity indicates that capture and shearing did not reduce the breeding success of radio-collared guanacos, or the early survival of their young.

\section{Effects on movement, density and population structure}

Capture stress may trigger a number of behavioural responses. These include flight-or-fight responses or development of behavioural strategies such as seeking refuge and waiting before returning, which was observed in roe deer Capreolus capreolus in response to capture, handling and fitting of a collar (Morellet et al., 2009). In contrast, our results indicate that live capture, shearing and release in the Reserve triggered dispersion by guanacos. After shearing there were smaller groups, indicating that some animals moved away from the disturbed area. Telemetry data indicated that there was increased movement during the days following capture, which may account for the larger home range sizes observed during the month after capture and shearing. This effect had not been described previously for wild populations of South American camelids and may have been initiated by the disturbance caused by setting up the camp and capture structures, and exacerbated by capture and shearing activities.

Increased movement in response to disturbance may only occur in some individuals, particularly in adult females, as evidenced by the larger reduction in female than male home range size the year after shearing. In contrast, in roe deer disturbance associated with capture temporarily reduced activity levels and had a stronger effect on males than females (Morellet et al., 2009). We found no correlation between the proportion of females with young and the home range size.

The effects of capture on the movement patterns of guanacos in the Reserve lasted $<_{1}$ month, and probably only a few days. It was not possible to differentiate the effects of capture and shearing from seasonal or inter-annual changes in movement. However, the reduction in home range size 1 month after shearing was probably the result of reduced movement associated with the calving season and termination of the winter migration, as a similar reduction was also observed 1 year after shearing.

The increase in group density and individual density 1 month after capture and shearing indicates that the dispersal effect was reversed. However, the mean group size decreased, which is consistent with the formation of reproductive groups (or family groups) at this time of year (November-December), which often do not exceed 10-12 individuals.

At the sheep ranch, round-up, capture and shearing of guanacos did not affect the population parameters analysed nor result in increased movement of guanacos. During 4 years we studied 660 guanaco groups in post-shearing surveys and recorded only one shorn guanaco outside the 5,000-ha paddocks in which the animals were shorn ( $\mathrm{P}$. Carmanchahi., unpubl. data). At this site guanacos seemed to exhibit similar behaviour in response to disturbance, moving away from the shearing corral, but remained within the paddock.

Territorial stability following shearing was also observed in radio-collared guanacos on a private ranch in Patagonia (Rey et al., 2012b) and in vicuñas Vicugna vicugna in northwest Argentina (Arzamendia \& Vilá, 2012).

\section{Effects on spatial distribution}

Studies have shown that spatial distribution in mammals is influenced by (1) physiological factors, such as body size (Swihart et al., 1988), sex and age (Relyea et al., 2000), and reproductive status (Bertrand et al., 1996), (2) ecological factors, such as intra- (Riley \& Dood, 1984) and interspecific competition (Loft et al., 1993), and trophic level (Harestad \& Bunnell, 1979), and (3) environmental factors, such as season, (Nicholson et al., 1997) and the availability of forage (Relyea et al., 2000) and water (Bowers et al., 1990). However, few studies have investigated the short-term effects of anthropogenic activities, such as management of wildlife, on spatial distribution.

At the sheep ranch, spatial distribution of guanacos appeared to be affected by management, as guanaco density decreased near the shearing corral. Guanacos were concentrated at sites far from the shearing corral but did not leave the paddock. At the Reserve, however, there was no 
clear effect of management on the spatial distribution of guanacos. The absence of physical barriers within the Reserve allows animals to move more freely away from the site of the corral and camp, and therefore we did not observe differences in the pattern of spatial distribution for each distance interval before and after assembly of the camp.

\section{Conclusion and management implications}

The methods used for capture and handling of a wild species may determine the effect of such management interventions on the physiological, behavioural and population parameters of the species. If capture and handling are carried out in accordance with animal welfare standards, physiological stress (Carmanchahi et al., 2011), behavioural stress (Taraborelli et al., 2011) and mortality after shearing (Carmanchahi et al., 2011) can be reduced. However, we found that capture and handling of guanacos had shortterm spatial and temporal effects on population parameters, with our results suggesting a dispersion effect among guanacos that were captured and shorn. In an open area groups moved away from the area where shearing took place, with shorn individuals moving $>13 \mathrm{~km}$ the first day. Sedentary populations also dispersed in response to handling but temporal patterns of individual and group density and group sizes were not modified within the managed paddock. In contrast, the spatial pattern was modified, with guanacos concentrated in areas far from the capture corral.

Our results support the hypothesis that the effects of capture and shearing of wild guanacos differ in sedentary and migratory populations. The adaptive importance of migratory movements is to guarantee favourable conditions for the existence and reproduction of the population. The delineation of grazing paddock by wire fences in Patagonia has led to a disruption of migratory paths of guanacos and the establishment of sedentary populations. A similar effect was observed in pronghorns Antilocapra americana in Texas, where migration appears to have been truncated by fences (Hailey \& DeArment, 1969). This significant anthropogenic factor has implications for the survival of guanacos because it may prevent animals from searching for new places with better environmental conditions. Fencing may also increase the local density of both livestock and wildlife in an area, preventing the natural rotation of use of food resources and seasonal recovery of pastures, and leading to degradation of vegetation and starvation of animals (Boone \& Thompson Hobbs, 2004). Our results show that capture and shearing of wild guanacos disturb population parameters significantly but for a relatively short period. Specifically, we documented dispersion and group disruption, similar to the findings of Sarno et al. (2009) for vicuñas, which if not minimized by appropriate management could have a negative effect on social composition and population dynamics. We recommend that management authorities do not allow pre- and post-partum round-up and shearing in the same year. Although we did not measure the effect of this activity on the mother-calf relationship we cannot rule out disruption, and therefore we recommend that after postpartum shearing mothers and their calves are reunited in corrals before release. The management of wild guanacos for live-shearing, if based on high standards of animal welfare and monitored closely, could contribute to the sustainable use and conservation of the species as well as to the socioeconomic development of the region.

\section{Acknowledgements}

This work was funded by CONICET PIP No. 11220100100386, ANPCyT-PICT 1305/2010 and PICT 34120/2005. We thank Cooperativa Payun Matrú members, park rangers, the government authorities of Mendoza province, and David Garrido. The project was approved by the Department of Renewable Natural Resources of Mendoza province (Resoluciones 117/09; 795/10, DRNRSecretaría de Medio Ambiente), and the Wildlife Agency of Río Negro province. We thank Dr Heiko Wittmer and an anonymous reviewer for their comments, which helped improve this article.

\section{References}

Arzamendia, Y. \& Vilá, B. (2012) Effects of capture, shearing, and release on the ecology and behavior of wild vicunas. The Journal of Wildlife Management, 76, 57-64.

Baldi, R., Albon, S.D. \& Elston, D.A. (2001) Guanacos and sheep: evidence for continuing competition in arid Patagonia. Oecologia, $129,561-570$

Baldi, R., Novaro, A., Funes, M., Walker, S., Ferrando, P., Failla, M. \& Carmanchahi, P. (2010) Guanaco management in Patagonian rangelands: a conservation opportunity on the brink of collapse. In Wild Rangelands: Conserving Wildlife While

Maintaining Livestock in Semi-Arid Ecosystems (eds J. du Toit, R. Kock \& J. Deutsch), pp. 266-29o. Wiley-Blackwell, Chichester, UK.

Bertrand, M.R., DeNicola, A.J., Beissinger, S.R. \& Swihart, R.K. (1996) Effects of parturition on home ranges and social affiliations of female white-tailed deer. The Journal of Wildlife Management, 6o, 899-909.

Boone, R.B. \& Thompson Hoввs, N. (2004) Lines around fragments: effects of fencing on large herbivores. African Journal of Range \& Forage Science, 21, 147-158.

Bowers, M.A., Welch, D.N. \& Carr, T.G. (1990) Home range size adjustments by the eastern chipmunk, Tamias striatus, in response to natural and manipulated water availability. Canadian Journal of Zoology, 68, 2016-2020.

Buckland, S.T., Anderson, D.R., Burnham, K.P., LaAke, J.L., Borchers, D.L. \& Thomas, L. (2001) Introduction to Distance Sampling: Estimating Abundance of Biological Populations. Oxford University Press, Oxford, UK. 
Carmanchahi, P.D. \& Marull, C. (2012) Protocolo de Buenas Prácticas de Manejo de Guanacos (Lama guanicoe) Silvestres. South American Camelid Specialist Group (GECS-IUCN). Http://www. camelidosgecs.com.ar/pdf/ba_guanacos_2012.pdf [accessed 30 July 2013].

Carmanchahi, P.D., Ovejero, R., Marull, C., López, G.C., Schroeder, N., Jahn, G.A. et al. (2011) Physiological response of wild guanacos to capture for live shearing. Wildlife Research, 38 , 61-68.

CITES (2013) Convention on International Trade in Endangered Species of Wild Fauna and Flora. Appendices I, II and III. Http://cites.org/eng/app/appendices.php [accessed 26 June 2014].

Di Rienzo, J.A., Casanoves, F., Balzarini, M.G., Gonzalez, L., Tablada, M. \& Robledo, C.W. (2011) InfoStat v. 2011 User Manual. Grupo InfoStat, Córdoba, Argentina.

Franklin, W.L. \& Fritz, M.A. (1991) Sustained harvesting of the Patagonia guanaco: is it possible or too late? In Neotropical Wildlife Use and Conservation (eds J.G. Robinson \& K. H. Redford), pp. 317-336. The University of Chicago Press, Chicago, USA.

Hailey, T.L. \& DeArment, R. (1969) Drought and fences restrict pronghorn. Texas Parks and Wildlife, 27, 6-11.

Harder, J.D. \& Kirkpatrick, R.L. (1994) Physiological methods in wildlife research. In Research and Management Techniques for Wildlife and Habitats (ed. T.A. Bookhout), pp. 275-306. The Wildlife Society, Bethesda, USA.

Harestad, A.S. \& Bunnell, F.L. (1979) Home range and body weight: a reevaluation. Ecology, 60, 389-402.

Hoffmann, J.P. (2004) Generalized Linear Models: an Applied Approach. Pearson Education, New York, USA.

León, R.J.C., Bran, D., Collantes, M., Paruelo, J.M. \& Soriano, A. (1998) Grandes unidades de vegetación de la Patagonia extra andina. Ecología Austral, 8, 125-144.

Loft, E.R., Kie, J.G. \& Menke, J.W. (1993) Grazing in the Sierra Nevada: home range and space use patterns of mule deer as influenced by cattle. California Fish and Game, 79, 145-166.

Martínez Carretero, E. (2004) Provincia fitogeográfica de la Payunia. Boletín de la Sociedad Argentina de Botánica, 39, 195-223.

Montes, M.C., Carmanchahi, P.D., Rey, A. \& Funes, M.C. (2006) Live shearing free-ranging guanacos (Lama guanicoe) in Patagonia for sustainable use. Journal of Arid Environments, 64, 616-625.

Morellet, N., Verheyden, H., Angibault, J.-M., Cargnelutti, B., Lourtet, B. \& Hewison, M.A.J. (2009) The effect of capture on ranging behaviour and activity of the European roe deer Capreolus capreolus. Wildife Biology, 15, 278-287.

Nicholson, M.C., Bowyer, R.T. \& Kie, J.G. (1997) Habitat selection and survival of mule deer: tradeoffs associated with migration. Journal of Mammalogy, 78, 483-504.

Pollock, K.H., Winterstein, S.R., Bunck, C.M. \& Curtis, P.D. (1989) Survival analysis in telemetry studies: the staggered entry design. The Journal of Wildlife Management, 53, 7-15.

R Development Core Team (2012) R: A Language and Environment for Statistical Computing. R Foundation for Statistical Computing, Vienna, Austria.
Raedeke, K.J. (1979) Population dynamics and socioecology of the guanaco (Lama guanicoe) of Magallanes, Chile. $\mathrm{PhD}$ thesis. University of Washington, Seattle, USA.

Relyea, R.A., Lawrence, R.K. \& Demarais, S. (2000) Home range of desert mule deer: testing the body-size and habitat productivity hypotheses. The Journal of Wildlife Management, $64,146-153$.

Rey, A., Novaro, A.J. \& Guichón, M.L. (2012a) Guanaco (Lama guanicoe) mortality by entanglement in wire fences. Journal for Nature Conservation, 20, 280-283.

Rey, A., Novaro, A.J., Sahores, M. \& Guichón, M.L. (2012b) Demographic effects of live shearing on a guanaco population. Small Ruminant Research, 107, 92-100.

Riley, S.J. \& Dood, A.R. (1984) Summer movements, home range, habitat use, and behavior of mule deer fawns. The Journal of Wildlife Management, 48, 1302-1310.

Sarno, R.J., GonZález, B.A., Bonacic, C., Zapata, B., O’Brien, S.J. \& Johnson, W.E. (2009) Molecular genetic evidence for social group disruption of wild vicunas Vicugna vicugna captured for wool harvest in Chile. Small Ruminant Research, 84, 28-34.

SCHroeder, N. (2013) Interacción entre el guanaco (Lama guanicoe) y herbivoros domésticos en el paisaje de La Payunia (sur de Mendoza, Argentina). PhD thesis. Universidad Nacional de Cuyo, Mendoza, Argentina.

Swihart, R.K., Slade, N.A. \& Bergstrom, B.J. (1988) Relating body size to the rate of home range use in mammals. Ecology, 69, 393-399.

Taraborelli, P., Ovejero, R., Schroeder, N., Moreno, P., Gregorio, P.F. \& Carmanchahi, P.D. (2011) Behavioural and physiological stress responses to handling in wild guanacos. Journal for Nature Conservation, 19, 356-362.

\section{Biographical sketches}

Pablo Carmanchahi's research focuses on the eco-physiological and population effects of guanaco management, and the development of sustainable alternatives for production on arid land. NATALiA SCHROEDER is interested in the ecological and anthropogenic factors affecting the spatial and temporal distribution of the guanaco. MARía José BOLgeri studies guanaco migration and predation on guanacos. SUSAN WALKER focuses on landscape ecology and wildlife conservation. MARTín FUnEs works on the conservation of Patagonian wildlife, and invasive species. JODI BERG is interested in guanaco ecology and the use of dogs for conservation. PAULA TARABORELLI studies behavioural ecology, and the effects of management on guanaco behaviour. RAMIRO OVEJERO studies the physiological effects of ecological and anthropogenic factors. P ABLO GREGORIO is interested in the nutritional quality of guanaco diet and its influence on physiological and ecological processes. PABLO MORENO focuses on the effects of parasitism on physiological and ecological processes. Andrés Novaro focuses on wildlife hunting, predator-prey interactions and conservation. 